\title{
Changes in hamstring strength after anterior cruciate ligament reconstruction with hamstring autograft and posterior cruciate ligament reconstruction with tibialis allograft
}

\author{
O-Sung Lee ${ }^{1}$ and Yong Seuk Lee $2^{2^{*}}$
}

\begin{abstract}
Aim: The aim of this study was to evaluate the changes in hamstring strength both after anterior cruciate ligament reconstruction (ACLR) with hamstring autograft followed by early rehabilitation and posterior cruciate ligament reconstruction (PCLR) with tibialis allograft followed by delayed rehabilitation.

Methods: Isokinetic strengths of the quadriceps and hamstring muscles and endurances were compared between a group of 20 patients undergoing PCLR using a tibialis anterior allograft and a 1:2 matched control group of 40 patients undergoing ACLR using a hamstring autograft at 2 years after the operations. Clinical results were also compared using stability tests and the Lysholm and the International Knee Documentation Committee scores.

Results: At 2 years after the operations, the torque deficit of the hamstring muscle in the involved leg compared to the uninvolved leg at both $60 \%$ and $120 \%$ was greater in the PCLR group than in the ACLR group $(60 \%), 21.8 \pm 14.0 \%$ versus $1.9 \pm 23.9 \%, P=0.0171 ; 120 \% \mathrm{~s}, 15.3 \pm 13.7 \%$ versus $-0.7 \pm 17.4 \%, p=0.012$, respectively). The peak torque of the hamstring muscle at $120 \%$ s was significantly lower in the involved leg than in the uninvolved leg only in the PCLR group $(71.3 \pm 31.9 \mathrm{~N} \cdot \mathrm{m}$ versus $81.9 \pm 27.8 \mathrm{~N} \cdot \mathrm{m}, P=0.005)$. There was no significant difference in the clinical results between the groups except for a side-to-side difference in the tibial translation on Telos stress radiographs.

Conclusion: The strength of the hamstring of the PCLR leg with allograft was significantly weaker than that of the unoperated leg after 2 years, whereas that of the ACLR leg with hamstring autograft maintained a similar level of strength compared to that of the uninvolved leg.
\end{abstract}

Level of evidence: Level III, case-control study.

Keywords: Anterior cruciate ligament, Posterior cruciate ligament, Reconstruction, Hamstring autograft, Tibialis allograft, Hamstring strength

\footnotetext{
* Correspondence: smcos1@hanmail.net

${ }^{2}$ Department of Orthopaedic Surgery, Seoul National University Bundang Hospital, Seongnam-si, South Korea

Full list of author information is available at the end of the article
}

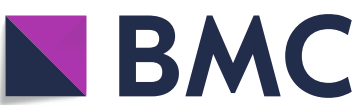

Part of Springer Nature (c) The Author(s). 2020 Open Access This article is licensed under a Creative Commons Attribution 4.0 International License, which permits use, sharing, adaptation, distribution and reproduction in any medium or format, as long as you give appropriate credit to the original author(s) and the source, provide a link to the Creative Commons licence, and indicate if changes were made. The images or other third party material in this article are included in the article's Creative Commons licence, unless indicated otherwise in a credit line to the material. If material is not included in the article's Creative Commons licence and your intended use is not permitted by statutory regulation or exceeds the permitted use, you will need to obtain permission directly from the copyright holder. To view a copy of this licence, visit http://creativecommons.org/licenses/by/4.0/. The Creative Commons Public Domain Dedication waiver (http://creativecommons.org/publicdomain/zero/1.0/) applies to the data made available in this article, unless otherwise stated in a credit line to the data. 


\section{Introduction}

In terms of restoration of knee function after anterior cruciate ligament reconstruction (ACLR) and posterior cruciate ligament reconstruction (PCLR), an improved understanding of the rehabilitation and recovery pattern of the muscles may be required [1-3]. Proper rehabilitation after ACLR results in good stability of the knee joint as well as the recovery of muscle power and sufficient range of motion (ROM) [4-8]. Regardless of the types of grafts used, excellent results regarding functional outcome and activity level have been reported with no differences between them [2, 9-13]. However, concerns over each graft type still exist, and certain advantages and disadvantages according to each graft type have been suggested [14-16]. In addition, ACLR using a hamstring autograft can give rise to a greater loss of knee flexor strength after surgery $[14,15]$.

Outcomes after PCLR have been reported to be inferior to those after ACLR [3, 17-19]. Recently, excellent functional outcomes after PCLR have been reported, with patients showing a return to their pre-injury level of activity because of the improved understanding of rehabilitation as well as advances in surgical techniques [17, 20-24]. However, a more conservative rehabilitation is preferred after PCLR than after ACLR [18, 20, 21]. Patients should avoid active flexion exercises after PCLR because these can result in posterior translation of the tibia and interfere with the healing process of related tissues $[3,19]$. Although the hamstring tendon could be saved during PCLR if other graft materials, such as tibialis anterior (TA) allografts, are used, there is a still concern regarding hamstring muscle weakness owing to inhibition of hamstring muscle exercises during the early postoperative period. However, information on the isokinetic changes in muscle strength and endurance in patients after PCLR is still lacking. In addition, the comparison of muscle strength and endurance after ACLR and PCLR has not been reported.

The purpose of this study was to evaluate the changes in hamstring strength after ACLR with hamstring autograft followed by early rehabilitation versus PCLR with tibialis allograft followed by delayed rehabilitation. We hypothesized that the strength of the hamstring muscles in both groups would be lower in the affected leg than in the unaffected leg.

\section{Materials and methods Patient selection}

This study compared the data that were obtained from patients who underwent ACLR with hamstring autograft and PCLR with TA allograft between 2014 and 2015. The ACLR and PCLR groups underwent a primary unilateral ligament reconstruction due to acute anterior cruciate ligament $(\mathrm{ACL})$ or posterior cruciate ligament
(PCL) injury without other major ligament or osseous surgical procedures. All tears of the ligament were observed by magnetic resonance imaging, and the diagnoses were confirmed using intraoperative arthroscopy. All ACLRs were performed using the trans-septal technique and hamstring muscle autograft and all PCLRs were performed using the trans-tibial technique and TA allograft $[25,26]$. This study included only patients within an interval of 6 weeks from trauma to surgery because the preoperative muscle condition in the chronic injury would vary with the time interval. Patients with concomitant meniscus tears and ligament injuries, which required other specific rehabilitation protocols other than the routine protocol, were excluded.

Seventy-nine patients treated via ACLR and 28 patients treated via PCLR met the inclusion criteria. A retrospective 1:2 matched-pair comparison was conducted. For each patient in the PCLR group, two patients were selected from the ACLR group, with the matching criteria of age ( \pm 1 year), sex and body mass index $\left( \pm 3 \mathrm{~kg} / \mathrm{m}^{2}\right)$. When there was no or only one patient in the ACLR group who matched the selection criteria for a patient in the PCLR group, all the patients were excluded. Finally, a total of 40 patients who underwent ACLR and 20 patients who underwent PCLR and who completed the isokinetic testing and clinical evaluation preoperatively and 2 years postoperatively were successfully included in this study. The demographic data of the two groups are shown in Table 1. There was no significant difference between the two groups in terms of age, height, weight, body mass index, sex, dominant side, incidence of meniscal repair and interval from trauma to surgery. This study obtained the approval of our institutional review board, and none of

Table 1 Patient demographics

\begin{tabular}{llll}
\hline & ACLR group & PCLR group & $P$ value \\
\hline Patients (knees), $n$ & 40 & 20 & \\
Age (years) & $30.7 \pm 10.4$ & $31.4 \pm 11.2$ & $0.248^{*}$ \\
Height (cm) & $172.8 \pm 5.4$ & $173.8 \pm 6.2$ & $0.607^{*}$ \\
Weight (kg) & $75.4 \pm 11.7$ & $76.5 \pm 10.2$ & $0.286^{*}$ \\
BMl (kg/m ${ }^{2}$ ) & $25.3 \pm 3.4$ & $25.4 \pm 3.6$ & $0.787^{*}$ \\
Sex (male/female), $n$ & $38 / 2$ & $19 / 1$ & $1.000^{* *}$ \\
Side (dominant/ & $24 / 16$ & $14 / 6$ & $0.573^{* *}$ \\
non-dominant), $n$ & & & \\
Meniscal repair, $n$ & $5(12.5 \%)$ & $2(10 \%)$ & $1.000^{* *}$ \\
Interval from trauma & $4.0 \pm 1.3$ & $4.2 \pm 1.7$ & $0.487^{*}$ \\
to surgery (weeks) & & & \\
\hline Values are presented as mean \pm standard devati & &
\end{tabular}

Values are presented as mean \pm standard deviation unless otherwise indicated The statistical significance was set at $P<0.05$

$A C L R$ anterior cruciate ligament reconstruction, $B M I$ body mass index, $P C L R$ posterior cruciate ligament reconstruction

*Derived with Student's $t$ test

**Derived with Pearson chi-square test 
the isokinetic results of this series have been used in other studies.

\section{Isokinetic test}

The isokinetic strength of the involved and uninvolved legs was measured using the BTE PrimusRS ${ }^{\mathrm{TM}}$ (Baltimore Therapeutic Equipment, Maryland and Colorado, USA) preoperatively and at 2 years postoperatively. The patients were seated in an upright position with a $90^{\circ}$ hip flexion on the testing device. After sitting, the chest, pelvis and thigh were immobilized using straps. After the uninvolved leg was tested, the involved leg was then tested. The ROM of the knee joint was set from $0^{\circ}$ to $70^{\circ}$. After warm-up repetitions, the measurements were repeated five times at an angular velocity of $60 \%$ s and 25 times at $120^{\circ} \mathrm{s}$. Peak torque was defined as the maximum value during the repetitions $(\mathrm{N} \cdot \mathrm{m})$ of flexion and extension. The extension and flexion peak torques of the involved leg were compared with those of the uninvolved leg, and the percentage of the torque deficit of each muscle in the involved leg compared to the uninvolved leg was also recorded. The hamstring to quadriceps ratio was calculated as the measurement of knee muscle balance. To determine muscular endurance, the total work was recorded as the work produced by the repetitions of consecutive extension and flexion of the knee joint at each angular velocity. All values measured during extension represented the quadriceps muscle strength, and those during flexion represented the hamstring muscle strength.

\section{Postoperative rehabilitation}

All patients in the two groups followed the home-based and standardized rehabilitation protocol according to the kind of reconstruction surgery they received. Regular follow-ups were performed at 2 weeks, 6 weeks, 3 months, 6 months, 1 year, and every year thereafter to provide adequate rehabilitation for each period. The ACLR group was permitted full weight bearing using a brace immediately after surgery. The goal for the patients was to gain $120^{\circ}$ of ROM 6 weeks after surgery. Closed kinetic chain exercises were started 6 weeks after surgery, and open kinetic chain exercises were started 12 weeks after surgery. A perturbation training program was started 6 weeks after surgery. Running was allowed at 3 months, with a return to sports activities 6 months after surgery. The PCLR group was permitted partial weight bearing using a brace immediately after surgery. Passive flexion exercises of the knee joint were permitted immediately after surgery. The ROM gradually increased to $90^{\circ}$ at 6 weeks. Hamstring muscle strengthening exercises were started at 12 weeks. Table 2 shows the routine rehabilitation protocols of our hospital for ACLR and PCLR in detail.

\section{Clinical evaluation}

The manual laxity was evaluated based on the anterior drawer test and pivot-shift test for the ACLR group, and the posterior drawer test for the PCLR group preoperatively and at every follow-up. As an indicator of knee stability, the side-to-side difference in the anterior translation on the Telos stress radiograph was used for the ACLR group and the difference in the posterior translation was used for the PCLR group. Flexion contracture and active maximal flexion were measured in the supine position using a goniometer. The clinical status was evaluated 1 day before surgery and every year after surgery using the Lysholm score and subjective and objective International Knee Documentation Committee (IKDC) scores.

\section{Statistical analysis}

All statistical analyses were performed using SPSS version 22.0 (IBM Corp., Armonk, NY, USA). Data description was based on means and standard deviations for continuous variables. The differences in continuous variables were analyzed using the Student's $t$ test or the Mann-Whitney test according to the appropriate normality tests. The differences in other categorical variables were analyzed with Pearson's chi-square test or Fisher exact test or linear-by-linear association. Statistical significance was set at $P<0.05$. A post-hoc power analysis was performed to assess the validity of the number of patients required in each group according to each parameter $(\alpha=0.05$, power $=80 \%)$.

\section{Results}

All isokinetic data of the patients who completed a 2year follow-up are shown in Table 3. There were no statistically significant differences between groups in any preoperative measurements.

In terms of the values measured postoperatively at 2 years, the torque deficit of the hamstring muscle in the involved leg compared to the uninvolved leg at both $60^{\circ} \%$ $\mathrm{s}$ and $120^{\circ} \mathrm{s}$ was greater in the PCLR group than in the ACLR group $\left(60^{\circ} / \mathrm{s}, 21.8 \pm 14.0 \%\right.$ versus $1.9 \pm 23.9 \%, P=$ $0.0171 ; 120^{\circ} / \mathrm{s}, \quad 15.3 \pm 13.7 \%$ versus $-0.7 \pm 17.4 \%, P=$ 0.012 , respectively), although there was no statistically significant difference in the absolute value of the hamstring peak torque between the groups. Additionally, there were no statistically significant differences between the groups regarding the peak torque of the quadriceps, torque deficit of the quadriceps muscle in the involved leg compared to the uninvolved leg, hamstring to quadriceps ratio or total work of both legs.

In addition, the involved and uninvolved legs in each group were compared. Peak torque of the hamstring muscle at $120^{\circ} / \mathrm{s}$ was significantly lower in the involved leg than in the uninvolved leg only in the PCLR group 
Table 2 Rehabilitation program for ACLR and PCLR

\begin{tabular}{|c|c|c|c|}
\hline Postoperative period & & ACLR & PCLR \\
\hline \multirow[t]{4}{*}{$\begin{array}{l}\text { Early postoperative phase } \\
\text { (0-6 weeks) }\end{array}$} & Joint mobility & $\begin{array}{l}0-90^{\circ} \text { ROM exercise until } 2 \text { weeks } \\
120^{\circ} \text { ROM increase until } 6 \text { weeks } \\
\text { Manual patellar mobilization }\end{array}$ & $\begin{array}{l}\text { Immediate immobilization in full extension } \\
\text { with posterior pad } \\
\text { Gradual increase to ROM } 90^{\circ} \text { until } 6 \text { weeks } \\
\text { Manual patellar mobilization }\end{array}$ \\
\hline & Weight bearing and brace & $\begin{array}{l}\text { Immediate full weight bearing } \\
\text { with brace }\end{array}$ & Partial weight bearing with $0^{\circ}$ locked brace \\
\hline & Exercise & $\begin{array}{l}\text { Active quadriceps (straight leg } \\
\text { raise, isometric quadriceps sets) } \\
\text { Active hamstring exercise } \\
\text { (hamstring sets, standing } \\
\text { hamstring curls at } 2 \text { weeks) } \\
\text { Ankle pump }\end{array}$ & $\begin{array}{l}\text { Supine passive ROM with both hands support } \\
\text { Prone passive flexion exercise } \\
\text { Calf raise and isometric quadriceps sets }\end{array}$ \\
\hline & Functional goal & $\begin{array}{l}\text { Normal gait pattern with single } \\
\text { clutch and unlocked brace at } \\
2 \text { weeks } \\
\text { Normal gait pattern without } \\
\text { assistance and brace at } 6 \text { weeks }\end{array}$ & $\begin{array}{l}\text { Early protected ROM } \\
\text { Caution against posterior tibial translation by } \\
\text { gravity, muscle action }\end{array}$ \\
\hline \multirow{4}{*}{$\begin{array}{l}\text { Intermediate postoperative } \\
\text { phase (6-12 weeks) }\end{array}$} & Joint mobility & Achieve more than $120^{\circ} \mathrm{ROM}$ & $90-120^{\circ} \mathrm{ROM}$ exercise until 12 weeks \\
\hline & Weight bearing and brace & $\begin{array}{l}\text { Brace off and start full weight } \\
\text { bearing at postoperative } 6 \text { weeks }\end{array}$ & Start full weight bearing with brace at 6 weeks \\
\hline & Exercise & $\begin{array}{l}\text { CKC exercise (squat } 0-60^{\circ} \text {, } \\
\text { lunge } 0-60^{\circ} \text {, leg press with } \\
\text { gradual progressive resistance), } \\
\text { stationary bike, stairs } \\
\text { (concentric and eccentric) }\end{array}$ & $\begin{array}{l}\text { Continue ROM exercise } \\
\text { Quad sets, single-leg squat, calf raise }\end{array}$ \\
\hline & Functional goal & $\begin{array}{l}\text { Single-leg squat to } 60^{\circ} \text {, equal } \\
\text { quad girth }\end{array}$ & $\begin{array}{l}\text { Normal gait pattern without assistance and } \\
\text { brace at } 12 \text { weeks } \\
\text { Increase ROM }\end{array}$ \\
\hline \multirow{4}{*}{$\begin{array}{l}\text { Return to activity phase } \\
\text { (12 weeks to } 6 \text { months) }\end{array}$} & Joint mobility & Full ROM & Achieve more than $120^{\circ}$ ROM exercise \\
\hline & Weight bearing \& brace & & $\begin{array}{l}\text { Brace off and start full weight bearing at } \\
12 \text { weeks }\end{array}$ \\
\hline & Exercise & $\begin{array}{l}\text { OKC exercise } \\
\text { Shuttle running, jumping rope, } \\
\text { light running, aqua jogging }\end{array}$ & $\begin{array}{l}\text { Hamstring strengthening exercise } \\
\text { Start CKC exercise (mini-squat } 0-45^{\circ} \text {, wall } \\
\left.\text { slides, leg press } 0-45^{\circ}\right) \\
\text { Progress CKC exercise } \\
\text { Straight line running, swimming (no frog kick), } \\
\text { jogging in pool }\end{array}$ \\
\hline & $\begin{array}{l}\text { Criteria to progress to } \\
\text { next phase }\end{array}$ & $\begin{array}{l}\text { Single-leg full squat } \\
\text { Single leg stance at least } 60 \mathrm{~s} \\
\text { Good landing form with bilateral } \\
\text { vertical and horizontal jumping }\end{array}$ & $\begin{array}{l}\text { Full and pain-free ROM, normal gait, good to } \\
\text { normal quadriceps strength, no patellofemoral } \\
\text { complaints }\end{array}$ \\
\hline $\begin{array}{l}\text { Return to sports activity } \\
\text { (after } 6 \text { months) }\end{array}$ & Exercise & $\begin{array}{l}\text { Progressive running program, } \\
\text { hop testing and training, } \\
\text { progressive plyometrics, competitive } \\
\text { sports, progress to sports-specific drills }\end{array}$ & $\begin{array}{l}\text { Light sports, progress jogging and running } \\
\text { Competitive sports after } 9 \text { months }\end{array}$ \\
\hline
\end{tabular}

$A C L R$ anterior cruciate ligament reconstruction, $C K C$ closed kinetic chain, $O K C$ open kinetic chain, $P C L R$ posterior cruciate ligament reconstruction, $R O M$ range of motion

$(71.3 \pm 31.9 \mathrm{~N} \cdot \mathrm{m}$ versus $81.9 \pm 27.8 \mathrm{~N} \cdot \mathrm{m}, P=0.005)$. Total work at $60 \%$ s was lower in the involved leg than in the uninvolved leg in both ACLR and PCLR groups (ACLR, $695.0 \pm 237.0$ versus $819.0 \pm 225.8, \quad P=0.001$; PCLR, $578.2 \pm 350.7$ versus $812.5 \pm 325.1, P=0.022$, respectively), and at $120 \% \mathrm{~s}$ was significantly lower in the involved leg than in the uninvolved leg only in the PCLR group $(2422.5 \pm 1189.2$ versus $3108.5 \pm 1174.5, P=0.004)$ (Table 3 and Fig. 1). Additionally, peak torque of the quadriceps muscle at $60^{\circ} / \mathrm{s}$ was significantly lower in the involved leg than in the uninvolved leg in the ACLR group $(100.1 \pm 33.7 \mathrm{~N} \cdot \mathrm{m}$ versus $114.3 \pm 33.8 \mathrm{~N} \cdot \mathrm{m}, \quad P=$ $0.021)$.

In terms of the clinical results, there were no statistically significant differences between the two groups. Improvements in manual laxity tests were observed in both groups. There was no statistically significant difference in the postoperative values of ROM, Lysholm scores (ACLR versus PCLR, $86.6 \pm 14.4$ versus $86.8 \pm 8.3, P=$ 0.971 ) or subjective IKDC scores (ACLR versus PCLR, 


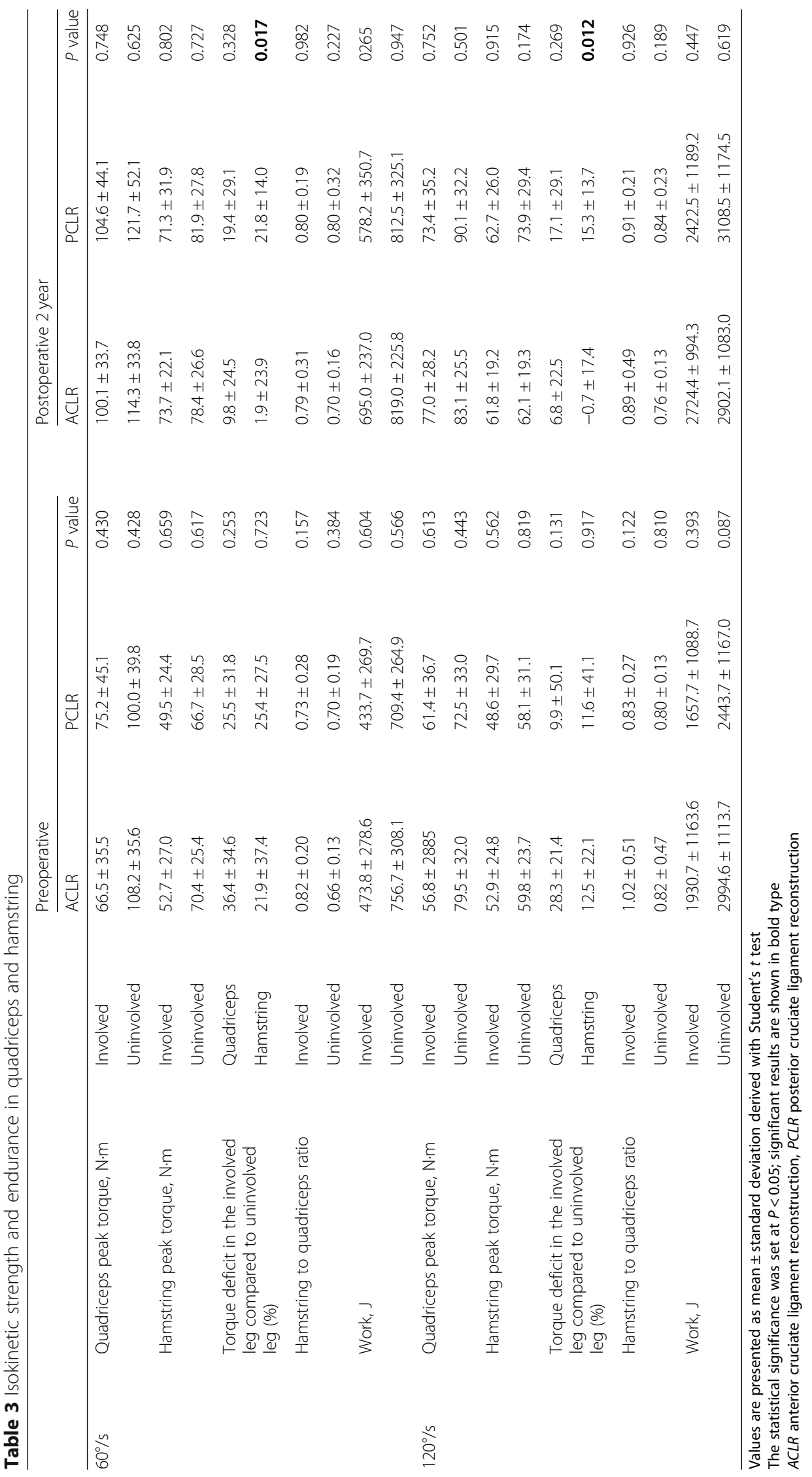




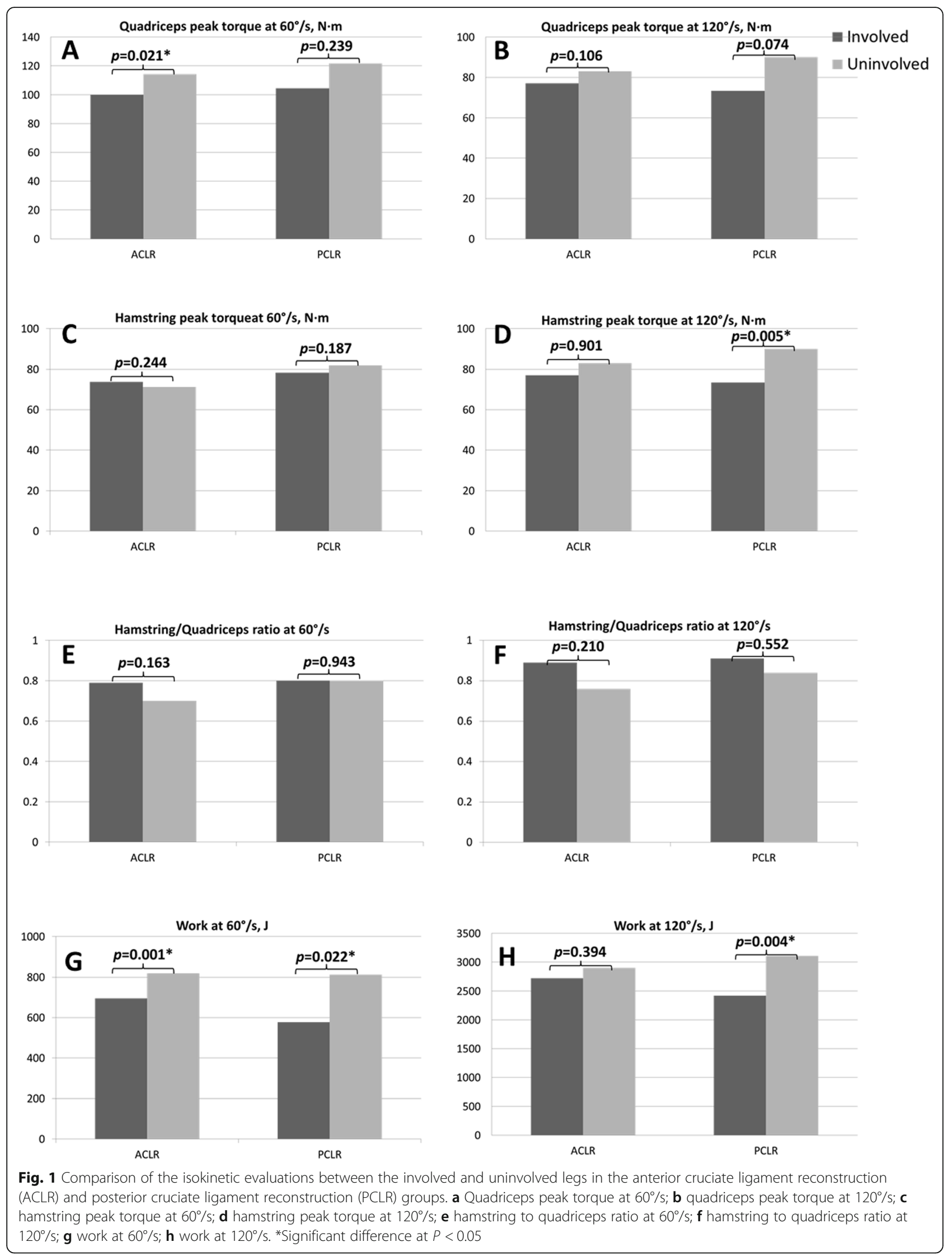


$90.4 \pm 16.4$ versus $84.3 \pm 11.3, P=0.548$ ). The objective IKDC scores also showed a similar result in the two groups $(P=0.104)$. Postoperative side-to-side differences in anterior tibial translation in the ACLR group was greater than that of posterior tibial translation in the PCLR group $(2.1 \pm 1.7 \mathrm{~mm}$ versus $4.1 \pm 2.6 \mathrm{~mm}, P=$ 0.045). However, the difference in the tibial translation between the groups has been widely accepted as a trait associated with each ACLR and PCLR surgery (Table 4).

A post-hoc power analysis on the hamstring peak torque at $60 \%$ and $120 \% \mathrm{~s}$ showed that a total sample size of 2054 and 10,124 specimens would be needed to achieve $80 \%$ power, respectively. The statistical power of the hamstring peak torque at $60 \%$ and $120 \%$ was $8.7 \%$ and $3.9 \%$, respectively. However, a post-hoc power

Table 4 Comparison of clinical outcomes between groups

\begin{tabular}{|c|c|c|c|}
\hline & ACLR group & PCLR group & $P$ value \\
\hline \multicolumn{4}{|l|}{$\begin{array}{l}\text { Anterior drawer test } \\
\text { (grade } 0 / 1 / 2 / 3 \text { ) }\end{array}$} \\
\hline Preoperative & $0 / 15 / 22 / 3$ & N/A & \\
\hline Postoperative & 27/13/1/0 & $\mathrm{N} / \mathrm{A}$ & \\
\hline \multicolumn{4}{|l|}{ Pivot-shift test (grade $0 / 1 / 2 / 3$ ) } \\
\hline Preoperative & $1 / 20 / 16 / 3$ & $\mathrm{~N} / \mathrm{A}$ & \\
\hline Postoperative & $34 / 6 / 0 / 0$ & N/A & \\
\hline \multicolumn{4}{|l|}{$\begin{array}{l}\text { Posterior drawer test } \\
\text { (grade } 0 / 1 / 2 / 3 \text { ) }\end{array}$} \\
\hline Preoperative & N/A & 0/8/11/1 & \\
\hline Postoperative & N/A & $5 / 11 / 4 / 0$ & \\
\hline \multicolumn{4}{|l|}{ Range of motion $\left(^{\circ}\right)$} \\
\hline Flexion contracture & $2.4 \pm 2.1$ & $2.1 \pm 1.8$ & $0.472^{*}$ \\
\hline Maximal flexion & $138.4 \pm 8.1$ & $137.2 \pm 8.1$ & $0.378^{*}$ \\
\hline \multicolumn{4}{|l|}{$\begin{array}{l}\text { Side-to-side difference of } \\
\text { anterior and posterior tibial } \\
\text { translation (mm) }\end{array}$} \\
\hline Preoperative & $7.4 \pm 2.7$ & $12.8 \pm 3.7$ & $0.027^{*}$ \\
\hline Postoperative & $2.1 \pm 1.7$ & $4.1 \pm 2.6$ & $0.045^{*}$ \\
\hline \multicolumn{4}{|l|}{ Lysholm score } \\
\hline Preoperative & $58.3 \pm 22.4$ & $50.3 \pm 16.4$ & $0.162^{*}$ \\
\hline Postoperative & $86.6 \pm 14.4$ & $86.8 \pm 8.3$ & $0.971^{*}$ \\
\hline \multicolumn{4}{|l|}{ IKDC subjective score } \\
\hline Preoperative & $55.4 \pm 15.9$ & $44.8 \pm 13.4$ & $0.013^{*}$ \\
\hline Postoperative & $88.1 \pm 12.9$ & $86.1 \pm 9.7$ & $0.548^{*}$ \\
\hline \multicolumn{4}{|l|}{ IKDC objective score } \\
\hline Preoperative (A/B/C/D) & 0/0/22/18 & $0 / 0 / 4 / 16$ & $0.013^{* *}$ \\
\hline Postoperative (A/B/C/D) & $27 / 12 / 1 / 0$ & $9 / 9 / 2 / 0$ & $0.104^{* *}$ \\
\hline
\end{tabular}

Values are presented as mean \pm standard deviation

The statistical significance was set at $P<0.05$

$A C L R$ anterior cruciate ligament reconstruction, IKDC International Knee Documentation Committee, N/A not applicable, $P C L R$ posterior cruciate ligament reconstruction

*Derived with Student's $t$ test

**Derived by linear-by-linear association analysis on the torque deficit of the hamstring muscle in the involved leg compared to the uninvolved leg showed that a total sample size of 17 specimens would be needed at both $60 \%$ and $120 \%$ s. The statistical power of the torque deficit of the hamstring muscle in the involved leg compared to the uninvolved leg at $60 \%$ and $120 \%$ s was $81.9 \%$ and $82.3 \%$, respectively.

\section{Discussion}

The principal finding of this study was that the peak torque of the hamstring in the leg undergoing PCLR was significantly weaker than that in the unoperated leg after 2 years, whereas that in the leg undergoing ACLR maintained a similar level of strength compared to the uninvolved leg, although the hamstring tendon was harvested only in the ACLR in this study. Additionally, despite the decreased strength of the hamstring muscle in the operated leg compared with the unoperated leg after PCLR, the clinical results after PCLR showed no significant difference compared to that after ACLR at 2 years.

Previous studies have shown decreased muscle strength after ACLR with a hamstring autograft. Keays et al. [27] reported that the recovery of hamstring muscle strength was slower than that of quadriceps muscle strength with a 6-month follow-up after ACLR using a hamstring autograft. Lee et al. [2] reported that the knee flexor strength recovered to $80 \%$ compared with the strength of the uninjured leg 1 year after ACLR using an autologous hamstring tendon. A study of 73 patients revealed that a more prominently decreased flexor power still exists at least 2 years after hamstring muscleharvested ACLR than after allografting [14]. To prevent weakness of the muscles, accelerated rehabilitation, including isokinetic flexor strengthening, has been recommended for patients after ACLR regardless of the type of graft used $[8,10,12,28,29]$. A recent systematic review of randomized controlled trials with deficient or reconstructed ACLs reported that the optimal time for the initiation of open kinetic chain exercises is at least 6 weeks post-reconstruction or postinjury [5].

In terms of PCLR, a more conservative rehabilitation has been traditionally used [3, 19-21, 30-32]. Recently, various rehabilitation protocols after PCLR have been suggested for muscle strengthening [23, 31-33]. The starting point of closed chain kinetic exercises varied from the immediate postoperative period to 12 weeks [17]. In terms of flexor strengthening, active hamstring muscle exercises are usually delayed for $\geq 12$ weeks after PCLR, whereas quadriceps muscle exercises are encouraged because of the agonistic function of the PCL [17, $22,30]$. However, some studies suggested that active hamstring muscle exercises delayed for 6-8 weeks of accelerated rehabilitation do not indicate a rapid increment of ROM $[17,19]$. Active flexion exercises of $0^{\circ}$ to 
$30^{\circ}$ of flexion in which the hamstring muscles cannot produce a posterior shear force were permitted [21, 22].

For early rehabilitation after PCLR, co-strengthening by calf raising, short arc leg press, and mini-squatting exercises could be performed [17, 19]. Despite these efforts to strengthen the extensor and flexor muscles concomitantly, a greater decrement in flexor power would be inevitable after PCLR compared to ACLR owing to the longer hamstring muscle inhibition. However, there is a lack of objective data on isokinetic testing observed after PCLR, and data compared with that of ACLR are even more scarce. A recent study showed no significant differences in preoperative strength and endurance of the hamstring muscles between untreated patients with ACL and PCL tears [1]. However, such a study did not compare the postoperative result of isokinetic testing between the two groups.

In our study, the deficit in the hamstring muscle of the involved leg compared with the uninvolved leg in the PCLR group persisted at 2 years, although there was no statistical difference in the absolute value of the hamstring peak torque between the groups. This finding may be because of the delayed rehabilitation after PCLR. Although we emphasized co-strengthening exercises and performed earlier rehabilitation after PCLR than the traditional PCLR rehabilitation, the expected hamstring muscle weakness persisted compared to the healthy leg. Therefore, further studies should be conducted on early PCLR rehabilitation that can strengthen the hamstring muscles without affecting the stability and function after PCLR. Additionally, we managed all patients with a home-based rehabilitation program in this study. Several studies reported that a home-based rehabilitation program is successful for the return of knee ROM and strength after ACLR [5, 34]. However, there is a lack of comparative study between home-based and physical therapy-supervised rehabilitation after PCLR. Therefore, further studies are necessary to determine whether a home-based rehabilitation is as effective after PCLR as after ACLR.

\section{Limitations}

This study has some limitations. First, this was a retrospective study with a relatively small sample size. However, we matched two groups according to our strict matching criteria and there were no significant differences in the demographic data between the groups. Second, the ROM of the isokinetic testing in this study was set only from $0^{\circ}$ to $70^{\circ}$. Therefore, we could not confirm the effect of ACLR and PCLR on deep flexion. Third, the total work was not measured separately for the flexion and extension, and so it was not possible to compare the endurances of the hamstring and quadriceps muscles. Finally, direct comparison between early and delayed rehabilitation protocol within each ACLR and PCLR group is required to determine the exact reason for hamstring deficit only after PCLR.

\section{Conclusions}

The strength of the hamstring in the leg undergoing PCLR with allograft was significantly less than that of the unoperated leg after 2 years, whereas the leg undergoing ACLR with hamstring autograft maintained a similar level of strength compared to that of the uninvolved leg.

\section{Abbreviations \\ ACL: Anterior cruciate ligament; ACLR: Anterior cruciate ligament reconstruction; IKDC: International Knee Documentation Committee; PCL: Posterior cruciate ligament; PCLR: Posterior cruciate ligament reconstruction; ROM: Range of motion; TA: Tibialis anterior}

\section{Acknowledgements \\ Not applicable.}

\section{Authors' contributions}

Both authors initiated the study and participated in its design and coordination. O-SL collected and analyzed the data. YSL coordinated the clinical study. O-SL initiated and performed the study, analyzed the data, and wrote the manuscript. Both authors helped to draft the manuscript and both authors read and approved the final manuscript.

\section{Funding}

There was no funding source.

Availability of data and materials

All data generated or analyzed during this study are included in this published article.

\section{Ethics approval and consent to participate}

This article was approved by the institutional review board of Seoul National University Bundang Hospital under protocol number B-1609/362-104.

\section{Consent for publication}

Not applicable.

\section{Competing interests}

The authors declare that they have no competing interests.

\section{Author details}

'Department of Orthopaedic Surgery, Mediplex Sejong Hospital, Incheon, South Korea. ${ }^{2}$ Department of Orthopaedic Surgery, Seoul National University Bundang Hospital, Seongnam-si, South Korea.

Received: 24 March 2020 Accepted: 21 May 2020

Published online: 05 June 2020

\section{References}

1. Lee DH, Han SB, Lee JH, Lee SJ, Suh DW, Jeong HJ (2015) Quadriceps strength and endurance after posterior cruciate ligament tears versus matched group with anterior cruciate ligament tears. Arthroscopy 31:1097-1101

2. Lee DH, Lee JH, Jeong HJ, Lee SJ (2015) Serial changes in knee muscle strength after anterior cruciate ligament reconstruction using hamstring tendon autografts. Arthroscopy 31:890-895

3. Lim BO, Shin HS, Lee YS (2015) Biomechanical comparison of rotational activities between anterior cruciate ligament- and posterior cruciate ligament-reconstructed patients. Knee Surg Sports Traumatol Arthrosc 23: $1231-1238$

4. Czuppon S, Racette BA, Klein SE, Harris-Hayes M (2014) Variables associated with return to sport following anterior cruciate ligament reconstruction: a systematic review. Br J Sports Med 48:356-364 
5. Kruse LM, Gray B, Wright RW (2012) Rehabilitation after anterior cruciate ligament reconstruction: a systematic review. J Bone Joint Surg Am 94: 1737-1748

6. Lentz TA, Zeppieri G Jr, Tillman SM, Indelicato PA, Moser MW, George SZ, Chmielewski TL (2012) Return to preinjury sports participation following anterior cruciate ligament reconstruction: contributions of demographic, knee impairment, and self-report measures. J Orthop Sports Phys Ther 42: 893-901

7. Meuffels DE, Poldervaart MT, Diercks RL, Fievez AW, Patt TW, Hart CP, Hammacher ER, Meer F, Goedhart EA, Lenssen AF, Muller-Ploeger SB, Pols MA, Saris DB (2012) Guideline on anterior cruciate ligament injury. Acta Orthop 83:379-386

8. Wright RW, Haas AK, Anderson J, Calabrese G, Cavanaugh J, Hewett TE, Lorring D, McKenzie C, Preston E, Williams G, MOON Group (2015) Anterior cruciate ligament reconstruction rehabilitation: MOON guidelines. Sports Health 7:239-243

9. Anderson MJ, Browning WM 3rd, Urband CE, Kluczynski MA, Bisson LJ (2016) A systematic summary of systematic reviews on the topic of the anterior cruciate ligament. Orthop J Sports Med 4:2325967116634074

10. Failla MJ, Arundale AJ, Logerstedt DS, Snyder-Mackler L (2015) Controversies in knee rehabilitation: anterior cruciate ligament injury. Clin Sports Med 34:301-312

11. Hamrin Senorski E, Samuelsson K, Thomee C, Beischer S, Karlsson J, Thomee R (2017) Return to knee-strenuous sport after anterior cruciate ligament reconstruction: a report from a rehabilitation outcome registry of patient characteristics. Knee Surg Sports Traumatol Arthrosc 25:1364-1374

12. Nyland J, Mattocks A, Kibbe S, Kalloub A, Greene JW, Caborn DN (2016) Anterior cruciate ligament reconstruction, rehabilitation, and return to play: 2015 update. Open Access J Sports Med 7:21-32

13. Oh JY, Kim KT, Park YJ, Won HC, Yoo Jl, Moon DK, Cho SH, Hwang SC (2020) Biomechanical comparison of single-bundle versus double-bundle anterior cruciate ligament reconstruction: a meta-analysis. Knee Surg Relat Res. https://doi.org/10.1186/s43019-020-00033-8

14. Kim JG, Yang SJ, Lee YS, Shim JC, Ra HJ, Choi JY (2011) The effects of hamstring harvesting on outcomes in anterior cruciate ligamentreconstructed patients: a comparative study between hamstring-harvested and -unharvested patients. Arthroscopy 27:1226-1234

15. Noh JH, Yi SR, Song SJ, Kim SW, Kim W (2011) Comparison between hamstring autograft and free tendon Achilles allograft: minimum 2-year follow-up after anterior cruciate ligament reconstruction using EndoButton and Intrafix. Knee Surg Sports Traumatol Arthrosc 19:816-822

16. Xergia SA, McClelland JA, Kvist J, Vasiliadis HS, Georgoulis AD (2011) The influence of graft choice on isokinetic muscle strength 4-24 months after anterior cruciate ligament reconstruction. Knee Surg Sports Traumatol Arthrosc 19:768-780

17. Kim JG, Lee YS, Yang BS, Oh SJ, Yang SJ (2013) Rehabilitation after posterior cruciate ligament reconstruction: a review of the literature and theoretical support. Arch Orthop Trauma Surg 133:1687-1695

18. Lee BK, Nam SW (2011) Rupture of posterior cruciate ligament: diagnosis and treatment principles. Knee Surg Relat Res 23:135-141

19. Lee YS, Jung YB (2013) Posterior cruciate ligament: focus on conflicting issues. Clin Orthop Surg 5:256-262

20. Edson CJ, Fanelli GC, Beck JD (2010) Postoperative rehabilitation of the posterior cruciate ligament. Sports Med Arthrosc 18:275-279

21. Fanelli GC (2008) Posterior cruciate ligament rehabilitation: how slow should we go? Arthroscopy 24:234-235

22. Hosseini Nasab SH, List R, Oberhofer K, Fucentese SF, Snedeker JG, Taylor WR (2016) Loading patterns of the posterior cruciate ligament in the healthy knee: a systematic review. PLoS One 11:e0167106

23. Jeon K (2016) Comparison of knee laxity and isokinetic muscle strength in patients with a posterior cruciate ligament injury. J Phys Ther Sci 28:831-836

24. Lee DY, Park YJ (2017) Single-bundle versus double-bundle posterior cruciate ligament reconstruction: a meta-analysis of randomized controlled trials. Knee Surg Relat Res 29:246-255

25. Ahn JH, Lee YS, Ko TS, Shin JY (2016) Accuracy and reproducibility of the femoral tunnel with different viewing techniques in the $A C L$ reconstruction. Orthopedics 39:e1085-e1091

26. Lee YS, Ko TS, Ahn JH, Kang SG, Choi UH, Elazab A, Lee HR (2016) Comparison of tibial tunnel techniques in posterior cruciate ligament reconstruction: C-arm versus anatomic fovea landmark. Arthroscopy 32 : 487-492
27. Keays SL, Bullock-Saxton JE, Newcombe P, Keays AC (2003) The relationship between knee strength and functional stability before and after anterior cruciate ligament reconstruction. J Orthop Res 21:231-237

28. Adams D, Logerstedt DS, Hunter-Giordano A, Axe MJ, Snyder-Mackler L (2012) Current concepts for anterior cruciate ligament reconstruction: a criterion-based rehabilitation progression. J Orthop Sports Phys Ther 42: 601-614

29. Paschos NK, Howell SM (2016) Anterior cruciate ligament reconstruction: principles of treatment. EFORT Open Rev 1:398-408

30. Forsythe B, Haro MS, Bogunovic L, Collins MJ, Arns TA, Trella KJ, Shewman EF, Verma NN, Bach BR Jr (2016) Biomechanical evaluation of posterior cruciate ligament reconstruction with quadriceps versus achilles tendon bone block allograft. Orthop J Sports Med 4:2325967116660068

31. Cavanaugh JT, Saldivar A, Marx RG (2015) Postoperative rehabilitation after posterior cruciate ligament reconstruction and combined posterior cruciate ligament reconstruction-posterior lateral corner surgery. Oper Tech Sports Med 23:372-384

32. Vaquero-Picado A, Rodriguez-Merchan EC (2017) Isolated posterior cruciate ligament tears: an update of management. EFORT Open Rev 2:89-96

33. Cury dPL, Kiyomoto HD, Rosal GF, Bryk FF, de Oliveira VM, de Camargo OP (2015) Rehabilitation protocol after isolated posterior cruciate ligament reconstruction. Rev Bras Ortop 47:421-427

34. Grant JA, Mohtadi NG (2010) Two- to 4-year follow-up to a comparison of home versus physical therapy-supervised rehabilitation programs after anterior cruciate ligament reconstruction. Am J Sports Med 38:1389-1394

\section{Publisher's Note}

Springer Nature remains neutral with regard to jurisdictional claims in published maps and institutional affiliations.
Ready to submit your research? Choose BMC and benefit from:

- fast, convenient online submission

- thorough peer review by experienced researchers in your field

- rapid publication on acceptance

- support for research data, including large and complex data types

- gold Open Access which fosters wider collaboration and increased citations

- maximum visibility for your research: over $100 \mathrm{M}$ website views per year

At BMC, research is always in progress.

Learn more biomedcentral.com/submissions 